\title{
A compartmental model of an identified Drosophila larval motoneuron for investigating functional effects of ion channel parameters
}

\author{
Cengiz Günay ${ }^{1 *}$, Logesh Dharmar ${ }^{1}$, Fred Sieling ${ }^{1,2}$, Richard A Baines ${ }^{3}$, Astrid A Prinz ${ }^{1}$ \\ From Twenty First Annual Computational Neuroscience Meeting: CNS*2012 \\ Decatur, GA, USA. 21-26 July 2012
}

Drosophila is a powerful genetic model system for investigating neuronal function. Several important membrane ion channel genes, such as voltage-gated sodium and potassium channels, were first identified and isolated in the fruit fly. Technical advances in experimental methods have recently made possible direct electrophysiological recording of ionic currents in central neurons, allowing the genetic advantages of this system to be applied to analysis of cellular and circuit function and homeostasis.

An important open question is the functional effect of channel splice variants, which have recently been found in Drosophila neurons [1]. The composition of splice variants, which result in the observed sodium current, changes in an activity-dependent manner in seizure mutant Drosophila (personal communication with W-H Lin, R Marley, and RA Baines) and may be the underlying cause of the increase of the persistent component of the sodium current [2]. Because of experimental limitations, computational modeling is essential for understanding the functional implications of this change.

We previously presented a computational approach to determine the full set of biophysical parameters of the sodium channel splice variants [3]. We then replicated combinations of these splice variants observed in flies and inserted them into a minimal, isopotential spiking model neuron with transient and persistent sodium, delayed-rectifier, and A-type potassium channels. This isopotential model was limited to reproducing only some firing properties of real neurons because of the morphological distribution of ion channels in these neurons. Specifically, sodium channels that are responsible

\footnotetext{
* Correspondence: cgunay@emory.edu

'Dept. Biology, Emory University, Atlanta, Georgia 30322, USA

Full list of author information is available at the end of the article
}

for action potential initiation are located far from the soma where the recordings are made.

In the present work, we improve this model neuron by including morphological details. We take the morphological information from identified larval aCC abdominal dorsomedial motoneurons, which innervate the dorsal muscles [4]. A two-compartment version of the model is used to assess effects of changing sodium channel properties. This neuron model allows investigating the effect of sodium channel splice variants by varying half-activation and inactivation voltages and ratio of a persistent component to mimic changes observed in sodium channel current properties in seizure mutants. We further analyze the effect that changes in synaptic input observed in seizure mutants have on the output neuronal activity.

\section{Acknowledgements \\ Career Award at the Scientific Interface (CASI) from the Burroughs Wellcome Fund awarded to AAP. Postdoctoral Fellowship from Epilepsy Foundation of America awarded to CG. Experimental data collected by Dr. V Wolfram and Dr. R Marley in lab of RAB. Dr. R Clewley (Georgia State Univ.) and Dr. M Herrera-Valdez (Arizona State Univ.) helped with modeling. M Zwart (Cambridge University, U.K.), provided morphological reconstruction. Morphology analyzed with Neuron, NeuronLand (James Ogden) and neuroConstruct (Padraig Gleeson) software.}

\section{Author details}

${ }^{1}$ Dept. Biology, Emory University, Atlanta, Georgia 30322, USA. ${ }^{2}$ Biomedical Engineering Dept., Georgia Inst. Tech. and Emory Univ., Atlanta, Georgia, USA. ${ }^{3}$ Life Sciences, University of Manchester, Manchester M13 9PT, UK.

Published: 16 July 2012

\section{References}

1. Lin W-H, Wright DE, Muraro NI, Baines RA: Alternative Splicing in the Voltage-Gated Sodium Channel DmNa(v) Regulates Activation, Inactivation, and Persistent Current. J. Neurophysiol 2009, 102(3):1994-2006. 
2. Marley R, Baines RA: Increased persistent $\mathrm{Na}+$ current contributes to seizure in the slamdance bang-sensitive Drosophila mutant. J Neurophysiol 2011, 106(1):18-29.

3. Günay C, Dharmar L, Sieling F, Baines RA, Prinz AA: A novel model of an identified Drosophila crawl motoneuron for investigating functional effects of ion channel type across larval developmental stages. BMC Neuroscience 2011 2011, 12(Suppl 1):P258.

4. Landgraf $M$, Bossing $T$, Technau G, Bate M: The origin, location, and projections of the embryonic abdominal motorneurons of Drosophila. $J$ Neurosci 1997, 17(24):9642-9655.

doi:10.1186/1471-2202-13-S1-P66

Cite this article as: Günay et al: A compartmental model of an identified Drosophila larval motoneuron for investigating functional effects of ion channel parameters. BMC Neuroscience 2012 13(Suppl 1): P66.

\section{Submit your next manuscript to BioMed Central} and take full advantage of:

- Convenient online submission

- Thorough peer review

- No space constraints or color figure charges

- Immediate publication on acceptance

- Inclusion in PubMed, CAS, Scopus and Google Scholar

- Research which is freely available for redistribution

Submit your manuscript at www.biomedcentral.com/submit 